\title{
Exploration and Summary of Establishing the Characteristic Course of Olunchun Original Ecological Music
}

\author{
Sun Xiaofei* , Xu Zuping* \\ Heihe College, Heihe Heilongjiang 164300
}

Keywords: Characteristic Course; Original Ecology; Exploration

\begin{abstract}
The characteristic curriculum is a school-based curriculum which can best embody its unique, stable and high-quality personality in the aspects of teaching ideas, curriculum setting, teaching methods and teaching effects. In local colleges and universities, the characteristic curriculum will have a significant impact on the school running ideology, the emergence of innovative teaching strengths and the shaping of the school image. The training goal of music specialty in local normal universities is to train music talents with modern educational thought, innovative spirit and certain personal professional characteristics. The construction of Olunchun original ecological music course is an important reflection of the characteristic education of music specialty in many local normal universities.
\end{abstract}

\section{The Development Value of Olunchun Original Ecological Music Characteristic Course}

Local folk music culture curriculum is designed and developed by local colleges and universities according to the actual situation of local cultural resources to adapt to the development of students and promote the development of local society. By presenting the history and development status of music culture in the region, learning the rich folk arts and Humanities knowledge, the course will help students better serve the local economic construction and cultural and educational undertakings in the future.

\subsection{Olunchun original ecological music is an important development of music teaching}

Normal colleges and universities are the main training bases for teachers in primary and secondary schools in China. The curriculum construction of music major in normal universities is mainly centered on the requirements of basic art education. China's long-standing, extensive and profound folk music is the local art created and spread by the working people in history to meet their social and spiritual needs. It contains rich social, historical and cultural connotations, reflects the unique life interest and aesthetic concept of the working people, is the foundation of Chinese national art and culture, and is an important resource of Contemporary Art education. In the current curriculum reform of basic education in China, actively developing and rationally utilizing all kinds of curriculum resources inside and outside schools has become an important measure to implement 
the new music curriculum in primary and secondary schools. The Ministry of Education's "Primary School Music Curriculum Standards" points out that "in addition to the national curriculum, local and school should develop music curriculum resources with regional, ethnic and school characteristics in the light of local human geographical environment and national cultural traditions" and "be good at using the local folk music resources in music teaching so that students can be nurtured by the national music culture from an early age". According to the strategy of threelevel management of national, local and school-based curriculum, many primary and secondary schools have closely linked the local ethnic cultural resources with the content of textbook teaching, which has become an important expansion of music classroom teaching. Primary and secondary school students have been influenced by local folk culture in their growth process. Introducing local folk culture learning content into the classroom can be most loved and accepted by children living in this region's ecological environment. The rich and colorful local folk art makes the classroom teaching more active and exciting, greatly improves the students'aesthetic interest, broadens the classroom teaching content, enriches the knowledge connotation of the curriculum, and enhances the students' love for their homeland. The introduction of Olunchun original ecological music has not only achieved remarkable results in classroom teaching, but also aroused social awareness of the protection of national culture, making primary and secondary schools an important position for the protection, inheritance and development of Olunchun original ecological music culture. The expansion of local folk art in music curriculum of basic education also puts forward new requirements for the training of music education talents in normal universities.

\subsection{Olunchun original ecological music is a valuable curriculum resource}

With the increasing frequency of international exchanges, the collision of various cultures in the world becomes more intense. We should pay more attention to the ecological protection of national cultures in the process of accepting and absorbing multicultures from different countries. Music majors in normal universities in China have been following the professional system centered on European music theory and supplemented by some national music courses for many years. Considering the applicability for the whole country, the current textbooks of national folk music in normal universities generally only introduce several representative ethnic groups. Our country has a vast territory and many nationalities, and the ecological environment varies greatly from place to place. Traditional folk arts are varied. The rich folk music resources possessed by all parts of the country contain tremendous artistic value and are the basis and source of the music culture of the whole Chinese nation. Folk music culture is closely related to local social life and humanistic environment. It is a great waste for music teaching in teachers'colleges to make full use of these precious cultural resources. Combining the representative of Chinese national music culture with the local characteristic music culture is the need of constructing the complete knowledge structure of national music for music students in local normal universities. Therefore, Music Majors in local normal universities use local cultural resources to set up distinctive local folk music courses so that students can understand local folk art and local cultural environment at the University stage. When they go to educational posts, they can also connect their classroom teaching with local cultural life, and cultivate students'love for the motherland and their hometown. On the stage of music education, they can carry out colorful and lively music teaching and interpretation.

\subsection{To study local folk music and promote the development of the inheritance}

Local colleges and universities are established in a certain region, and undertake the task of training qualified personnel for local economic construction and social development. Local colleges and universities should rely on local economy and regional culture, take the cultural history, human 
landscape, folk customs and folk art of the school's area as a kind of teaching resources to develop and utilize, and actively support the local economic development and cultural construction. The splendid folk music everywhere is our precious national cultural heritage and an important part of the world art treasure house. However, with the invasion of various modern powerful cultures, national cultures are experiencing unprecedented impact, and many folk music with national and regional characteristics are gradually shrinking, or even on the verge of disappearance. How to carry forward the national music culture in the modern social environment and how to inherit the excellent folk music art under the background of multi-music culture are the social problems that local government departments and the whole society should pay close attention to. Colleges and universities have a large teaching and scientific research team, which is an important force in the study of national culture. While deeply understanding and learning local music culture, they give full play to their scientific research advantages, actively carry out the excavation, rescue, research and inheritance of folk music cultural heritage, help local governments protect local national culture, rebuild local cultural ecology and make use of local music and literature. It is the duty-bound responsibility of local colleges and universities to turn resources into resources and promote local economic and cultural construction.

\section{The Development Strategy of Olunchun Original Ecological Music Characteristic Course}

After the orientation of curriculum objectives, the collection and combing of local music resources, the determination of curriculum content, the construction of curriculum structure, the formulation of teaching plans, the compilation of Curriculum textbooks and the establishment of teaching practice bases are the problems that need to be studied in the development of folk music characteristic curriculum.

\subsection{According to Oroqen's original ecological music and cultural resources}

Music, as one of the most common cultural forms in human society, closely adheres to and merges with various social and folk activities to form a variety of folk music and cultural phenomena. In order to develop the original ecological music culture curriculum in Oroqen, teachers'colleges should first conduct a comprehensive survey of the phenomena, forms and carriers of music culture in various folk activities in their respective regions, and thoroughly understand the distribution of local folk music culture resources, so as to lay a respectable and abundant curriculum resource foundation for the construction of characteristic courses. Then, in the vast resource bank, we can extract a certain history of formation and development, the form is relatively stable, the tune is widely circulated, and the popular art types and forms of expression are the teaching contents of the course. Compared with ordinary courses, Olunchun original ecological music culture characteristic course has different particularities. Its curriculum resources are mainly in the folk, its learning mode is mainly experience, and its implementation features are situational and flexible. Therefore, according to the principles of "people-oriented", "school-based" and "resource-based", we should determine the overall goal of characteristic curriculum construction and the plan of colleges and universities from the perspective of teaching talent cultivation, combine the knowledge and skills, process and method, emotion and value of the curriculum, and organize the implementation of curriculum teaching. To some extent, the teaching of courses will be constrained by many external factors. Many teaching practices should be carried out around local folk activities. Therefore, flexible teaching arrangements should be adopted to integrate school-based research and social practice organically, and constantly complement and improve in the process of implementation. 


\subsection{To adopt various ways of practical teaching and implement the process-oriented}

Originality, regionalism, popularity and popularity are the characteristics of folk art. Folk music, with its unique artistic charm, accompanies the development of local history and meets the spiritual and cultural needs of the local people. In addition to the fresh and fragrant contents of the original ecological music course in Oroqen Normal University, flexible and diverse teaching methods and zero-distance contact with folk music are the teaching features of the course. Therefore, on the basis of a comprehensive survey of the distribution of local music and cultural resources, villages, folk artists and mountains with more active folk music activities should be dealt with. The singers focus on investigating and establishing archives. Establish several off-campus practice teaching bases in the place where folk music occurs with relatively mature conditions and close connections, adopt open teaching methods, and participate in various local festivals and folk activities in the practice teaching bases; or invite folk artists and folk song masters to schools, so that the original ecological folk art can enter the elegant hall of higher education, and let students experience the original juice first-hand. Taste the touching charm of folk music, so that they re-recognize the artistic value of local music, stimulate students to love the national feelings of local folk art and culture.

\section{The Evaluation Method of Oroqen Original Ecological Music Teaching}

Teaching evaluation refers to the grasp of the reality and value judgment of educational activities, which involves the measurement and evaluation of people's educational behavior. The teaching objective of local music culture characteristic course is mainly students'understanding, learning and feeling of local folk music. Therefore, its educational evaluation should be formed rather than terminated, pluralistic rather than single, interactive rather than one-way. Teaching evaluation should pay attention not only to the knowledge and skills of the curriculum, but also to the students'emotions and attitudes. We should take the experience process, participation performance, research attitude and learning results of students'classroom teaching and practical activities as the main basis for curriculum evaluation, so that students can not only understand Olunchun original ecological music, but also grasp the expression methods of folk music initially, and cultivate their feelings for folk art. Regular teaching practice reports and performances are held to create more performance platforms for students to practice folk music. Through the study of the course, the students'interest in folk art will be guided to the level of scientific research, and the local folk music will be taken as the subject they are enthusiastic about, so that the course will develop to a higher level.

\section{Conclusions}

Olunchun original ecological music culture course, as a characteristic course of music specialty in local normal universities, is an attempt to combine subject specialty teaching with local culture. It is also a need for teachers to train excellent music talents to adapt to the development of basic education and social culture. With the continuous improvement of professional teaching quality and the strengthening of students'aesthetic concept of national culture, it will prove the importance of developing local characteristic courses. Local music culture characteristic curriculum should be continuously enriched, perfected and improved in the process of teaching implementation, so as to make music education in local normal universities more vibrant and energetic, and more suitable for the needs of the times for music education personnel training. 


\section{Acknowledgments}

Topic: This paper is the annual project of Heilongjiang Philosophy and Social Sciences Research Program. Name: Deep excavation and protective inheritance of Olunchun original ecological music and exploratory research on Teaching of highlighting local characteristics in Colleges and universities, No. 18YSE618.

\section{References}

[1] Primary School Music Curriculum Standards of the Ministry of Education [M]. People's Education Press, 2001.

[2] Reflections on Fang Tao's Music Education and Heritage of Traditional Culture [J]. Music Education and Creation, $2006:(6)$.

[3] Xue Hui briefly talked about the introduction of excellent folk music into music classes in primary and secondary schools [J]. Music education and creation 2007:(11).

[4] Zhongming Folk Music and Textbook Curriculum Development [J]. Music Education in Primary and Secondary Schools 2006:(3). 